CSID Working Paper Series

\#CSID-2012-003

\title{
Breaking the Elected Rules in a Field Experiment on Forestry Resources
}

\author{
Marco A. Janssen \\ Arizona State University, USA \\ François Bousquet \\ CIRAD, France \\ Juan-Camilo Cardenas \\ Universidad de los Andes, Colombia \\ Daniel Castillo \\ Javeriana University, Colombia \\ Kobchai Worrapimphong \\ Chulalongkorn University, Thailand
}

April 25, 2012

The Center for the Study of Institutional Diversity resides in the School of Human Evolution and Social Change at Arizona State University. CSID can be found on the internet at: http://csid.asu.edu/. CSID can be reached via email atcsid@asu.edu or via phone at (480)965-8318

(C2012 by M.A. Janssen, F. Bousquet, J-C. Cardenas, D. Castillo and K. Worrapimphong. All rights reserved. 


\section{Breaking the Elected Rules in a Field Experiment on Forestry Resources}

Marco A. Janssen ${ }^{\mathrm{a}}$, François Bousquet ${ }^{\mathrm{b}}$, Juan-Camilo Cardenas ${ }^{\mathrm{c}}$, Daniel Castillo ${ }^{\mathrm{d}}$, and Kobchai Worrapimphong ${ }^{\mathrm{e}}$

${ }^{a}$ Center for the Study of Institutional Diversity, Arizona State University, Tempe, AZ 85287;

${ }^{\mathrm{b}}$ CIRAD-GREEN, Campus Baillarguet, Montpellier, Cedex 5, France;

${ }^{c}$ Department of Economics, Universidad de los Andes, Calle 19A No. 1-37 Este (W-803), Bogotá, Colombia

${ }^{\mathrm{d}}$ Research Group on Institutions and Rural Development of the School of Environmental and Rural Studies. Universidad Javeriana, Transv. 4 \# 42-00 (Piso 8), Bogotá, Colombia

${ }^{\mathrm{e}}$ Department of Biology, Faculty of Science, Chulalongkorn University, Pathumwan Bangkok 10330, Thailand

Corresponding author:

Marco A. Janssen

School of Human Evolution and Social Change, Arizona State University

PO Box 872402

Tempe, AZ 85287-2402, USA

Marco.Janssen@asu.edu; Phone: 480965 4193; Fax: 4809657671

\section{Abstract}

Harvesting from common resources has been studied through experimental work in the laboratory and in the field. In this paper we report on a dynamic commons experiment, representing a forest, performed with different types of communities of resource users in Thailand and Colombia, as well as student participants. We find that all groups overharvest the resource in the first part of the experiment and that there is no statistical difference between the various types of groups. In the second part of the experiment, participants appropriate the common resource after one of three possible regulations is elected and implemented. There is less overharvesting after the rules are implemented, but there is a significant amount of rule breaking. The surprising finding is that Colombian villagers break the rules of the games more often than other groups, and even more so when they have more trust in members of the community. This observation can be explained by the distrust in externally proposed regulations due to the institutional and cultural context. 


\section{Introduction}

Communities are frequently able to govern their shared resources despite the temptation to overharvest(Ostrom, 1990). A tragedy of the commons is frequently avoided if resource users have the ability to participate in decision making on regulations and if there is graduated sanctioning, monitoring and enforcement, and trust among the resource users.

Notably, external interventions designed to improve the performance of the groups do not seem to lead to better performance. This is also observed in field experiments (Cardenas et al., 2000; Vollan, 2008). One explanation for this is the crowding-out behavior of group-oriented decisions that are initially made because of intrinsic motivations, but due to external interventions, end up with behavior that is more self-oriented. Crowding-out of pro-social behaviors has been found in various social dilemma situations. A classic example is blood donations. Titmuss (1970) found that voluntary arrangements in the UK led to higher quantities and quality of blood donated than the incentive-based US system. Donating blood is often done because of intrinsic motivation, not because of financial rewards.

Vollan (2008) found that external interventions that are enabling instead of restricting reduce the likelihood of crowding out. Furthermore, he found that the more people support the new regulation, the higher the compliance.

The experiments presented in this study focused on understanding the role that experience with resource management plays on decisions made in a common pool resource game. The experiment was framed as a forestry experiment and performed in rural villages and urban university campuses in Colombia and Thailand. The rural villages had forestry resources, fishery or irrigation as the main common resource uses.

In the second stage of the experiment we allow participants to elect one of three possible rules: a lottery, fixed rotation, and quotas, which include a pecuniary penalty on non-compliance. We found a high $(>50 \%)$ percentage of rule breaking when their elected rules were implemented. Although partial compliance reduced the rapid decline of the resource, the earnings did not increase due to the payment of penalties.

We found important differences between the communities that can explain the differences in the level of rule breaking. In some villages it is socially acceptable to ignore external regulations, and these were also the villages with the higher level of non-compliance. In contrast to crowding-out studies, the rules were broken from the start at a high level and the level of violation remained constant. Hence there seems to be no crowding out but merely a lack of internalization of the rule.

How the context alters the trade-offs between following institutional mandates and personal gains remains a crucial question in solving social dilemmas like these. Our results suggest that explicit rules may have different effects on behavior depending on the level of internalization of social norms, which, in turn, depends on the cultural context. Our ethnographic observation during the field work suggests that such is the case when comparing the different valuations that villagers in Thailand and Colombia may have of rules.

Based on earlier studies we define the following conjectures, which will be tested through our field experiments.

\section{Conjecture 1. Participants will overharvest the common resource and exhaust its stock as rapidly as possible.}

Since participants are not able to communicate, and the personal benefit from extracting one unit is much greater than the expected benefit of leaving it on the ground, we expect that groups will overharvest the common resource inducing a net social loss for the group.

\section{Conjecture 2. Regulations lead to less overharvesting.}

After the participants have elected a regulation, participants will reduce the average harvesting rate, either because the regulation works as a coordination device or because it imposes a private cost to violators.

Conjecture 3. Relevant resource management experience affects the behavior in the experiments. 
Results are different between the different type of villages, those with forestry and those without forestry experience. Furthermore, we expect a difference in results between villagers and student groups as found in forestry experiments in other locations (Ghate et al., 2011; Kluvánková-Oravská, 2011).

\section{Conjecture 4. Trust in other community members affects the behavior in the experiments.}

Based on results in other field experiments (and general findings of Poteete et al. 2010) we expect that more trust in others in the community will be a predictor of higher cooperative behavior, due to expectations of higher cooperation by other group members.

\section{Experimental design}

In the basic design we used in the lab and the field, the initial amount of the resource is 100 trees (see the appendix for the instructions of the experiment). In each round each of the five participants can take a maximum of 5 trees from the resource (Table 1). The game has a maximum duration of 10 rounds. The stock will regenerate in each round. For every 10 trees remaining in the resource, one tree is added as regrowth, with a maximum resource size of 100 trees. When the stock is below 25 trees, the maximum number of trees each individual is allowed to extract is given by Table 1 .

When participants collect as much as possible as fast as possible, the stock will be depleted in 5 rounds, and the trees collected by the group are 115 . When they cooperate and maximize the group earning over the 10 periods, the group total can increase to 165 (Figure 1).

After ten rounds the participants can vote for one of the three following rules, which will be enforced for another ten rounds, and restarting with a 100 units resource:

- Rule 1 (Lottery). Each round two participants are randomly drawn who can harvest. If somebody harvest when (s)he is not allowed to do so, a penalty may be applied. In each round a die is thrown, and when a six is through, an inspector comes and rule breakers get a penalty. The penalty consists of paying back the harvested amount plus an extra 3 tokens.

- Rule 2 (Rotation). A fixed schedule is defined where two participants are allowed to harvest each round. In round $1, \mathrm{~A}$ and $\mathrm{B}$ can harvest, then $\mathrm{C}$ and $\mathrm{D}$, then $\mathrm{E}$ and $\mathrm{A}$, etc. The same mechanism of monitoring and sanctioning is used as rule 1.

- Rule 3 (Property). Everybody has the right to harvest 0,1 or 2 units per round. If a higher amount is harvested, a die determines whether the participant is inspected, and if in violation returns back the harvest plus 3 tokens.

These rules were designed based on the most common rules found in field studies on common-pool resources. In our design, participants can vote for their preferred rules which will be implemented in a subsequent series of rounds if three or more players vote for it. If two rules get two votes, an additional round of votes between those two candidates is used to determine the final chosen rule. All rules are aimed at solving the resource dilemma by regulating the over extraction of the resource in the appropriation stage, and thus achieving the goal of sustaining the resource through all ten rounds and each of the five players harvesting an equal share of the resource over the duration of the game.

Ten rounds are played with the new rule implemented. The first round after the election has the same starting situation as round 1 of the experiment. If participants are selfish and rational the non-cooperative equilibria would be the same. The reason for this is that when expected earnings by breaking a rule is higher than complying with the rule. For rules 1 and 2 the expected penalty for breaking a rule is $8 / 6$ while gaining 5 
tokens if one is not allowed to harvest. For rule 3 the expected penalty is again $8 / 6$ but this time the gain is 3 tokens. Due to penalties, the expected group earnings in the non-cooperative equilibrium is reduced to 95 for rules 1 and 2, and $812 / 3$ for rule 3. The expected level of penalties for rules 1 and 2 is equal to have each round 3 players a $1 / 6$ probability being caught and pay $8(5+3)$ tokens for the first four rounds and $6(3+3)$ for the last round before the resource is depleted. This leads to an expected penalty of 20 tokens. For rule 3,5 players have each round the risk of being caught. This leads to an expected penalty of $331 / 3$ tokens.

If the rules are followed, the resource size declines only slowly (Figure 2). Since the resource is not fully depleted when the experiments end, the total earnings are 100 trees for all three rules. This is higher than the Nash equilibrium. If a group was able to coordinate to increase its earning, a profitable strategy would be to follow the rules for 6 rounds, and then harvest the maximal level for four rounds. This would lead to expected earnings of 144 for rules 1 and 2, and $1231 / 3$ for rule 3.

\section{Experimental setting}

The pencil and paper based experiments were held in six villages in Thailand and Colombia: three in each country. In one of the villages in each country the dominant resource use is a fishery, one a forest, and one an irrigation system (see Table 2). In Thailand, the experiments were performed in three separate locations of the Petchaburi watershed, which runs toward the west coast of the Gulf of Thailand. One of the villages is located is in the coastal area, and the other two are inland. The Colombian experiments were conducted in three different rural sites. The fishery community is represented by a village on Barú Island (a rural area of Cartagena, on the Caribbean coast). The irrigation community is located in the Fuquene lake basin area, located in the Andean region of Cundinamarca and Boyacá. And the forestry community is located in Salahonda, on the Pacific coast tropical forest area. For all these locations permission was given when needed by the heads of villages to perform experiments. The experiments were held during the first six months of 2007. Typically four days of experiments were followed by in-depth interviews with a sample of relevant stakeholders of the village.

The participants were recruited via word of mouth and flyers hung throughout the village inviting participants age 18 years and older to participate. Special effort was made to recruit adults from households engaged in the resource extraction of that village. This had an expected effect of gender bias in favor of males for most of the village sites. Only one member of a family was allowed to participate in the same session. Before the participants receive their payments, they fill out a general survey on their demographics and resource use within the village. The duration of an experimental session was about three hours and the typical earnings of the participants were worth between one and two days of wage labor.

At the end of the series of experiments a handful of people were identified for in-depth interviews. Those individuals were selected among the participants to be a representative sample of the community of resource users. At the end of the week, a session was organized to discuss the experiments.

Each of the forestry games was conducted with 4 groups of 5 people. As a result 20 persons participated in each of the six villages, leading to a total of 120 individuals. In 2008, the experiments were replicated by using the same protocol and incentives with university students in Bogota and Bangkok, with 20 students (4 sessions) in each city.

The average age of the villager participants was 39.9 years (Std. Dev 13.8), and 28\% percent of them were females. About two thirds of them reported living in their village for their entire life. Among the student participants the average age was 19.7 years and 50\% percent of them were females. The education level of the villagers varied. 12 percent of them had no formal education, and about 30 percent of them with some or complete primary education. Forty-three percent of the players had secondary education and only approximately 16 percent received technical or university training.

In the experiment, the participants know who else is participating, but they do not know the decisions of the other individuals during each of the 20 rounds that the experiment lasted for each group. Only the aggregate outcomes of the decisions are presented to the group in each round. They are not allowed to communicate with others during the experiment. Assistants were made available during the experiments for those participants who had difficulty with reading and/or arithmetic.

\section{Experimental results}


Figure 3 shows the average resource size over the rounds. The resource rapidly decreases over the rounds, but not as fast as the Nash prediction. In the first round about 20 out of a maximum of 25 trees is harvested. On average the resource is not completely depleted at the end of 10 rounds. After one of the three rules is implemented, the average resource size is sustained over the rounds at higher level than without the rules, but still below the group optimal strategy.

The average number of trees in the resource during stage 1 and stage 2 are given in Table 3 for the groups within each village. The average stock varies from 25 to 41 in stage 1, and from 41 to 61 , which shows that there is a substantial variation across villages. The forestry villages have the highest stock in stage 2 within in each country, and the student groups the lowest. The average level of the resource is 35.13 during the first 10 rounds, which significantly $(\mathrm{p}<0.001)$ increases to 50.32 trees during the second 10 rounds, using the Wilcoxon Matches-Pairs Signed-Ranks Test. The average group earnings during the first 10 rounds is 125.34 which drop to 113.28 in the second 10 rounds, after accounting for the penalties paid by those inspected. This difference is significant $(\mathrm{p}<0.001)$ using the Wilcoxon Matches-Pairs Signed-Ranks Test.

We also see that there is a high percentage of rule breaking, especially in villages in Colombia. Of those decision situations where persons were not allowed to harvest due to the enforced rules, Columbian villagers harvested between $70 \%$ and $83 \%$ of the time. Such levels were much lower for the Thailand cases as shown in Table 3. The fishery village in Thailand has the highest level of rule breaking among the Thai cases. However, the levels of rule breaking for students were similar and much lower in both countries.

In Figures 4 and 5 we depict the average earnings of all the villages over 10 rounds before and after the rule change. The group earning varies from 109 to 136 . Hence some groups mimic the Nash equilibrium (115), while others are between the Nash and the cooperative equilibrium (165). In rounds 11-20, group earnings decreased due to the payment of penalties for breaking the rules in addition to the lower number of trees harvested. Some groups lost more than 20 tokens from penalty payments. Some groups, especially the forestry and irrigation villages in Thailand kept a high amount of trees in the resource. Although they did not lose money to penalty payments, there was a high number of trees left at the end of the experiment. Further, Figure 5 shows that in both forestry villages, the number of trees left in the forest was higher than in the other two corresponding villages - that is, more trees were left in the forestry villages and therefore more money left on the table.

Does experience with forestry affect the actions participants take in this experiment? A first step in addressing this question is to see whether villages with forestry, other villages (irrigation and fishery) and students in an urban environment have different earnings.

During the first 10 rounds, groups from forestry villages, other villages and student groups do not have significantly different earnings nor do they have different levels of average resource stock. Using a two-tailed Mann Whitney test the p-values for earnings are 0.120 (forestry groups vs other villages), 0.328 (forestry groups vs student groups) and 0.881 (other villages vs student groups). Thai groups collect significantly more than Colombian groups $(126.7$ vs 132.1 , with $\mathrm{p}=0.016)$ due to more sustainable rates in the first rounds. The $\mathrm{p}-$ values for the average resource size are 0.528 (forestry vs other villages) 0.328 (forestry vs student groups), 0.238 (other villages vs student groups) and 0.014 (Thai vs Colombian groups). The earnings are significantly higher compared to the Nash equilibrium ( $p$-value $<0.001)$.

After the rules are elected, the villagers increase their resource size (p-value 0.008 for forestry groups, and 0.001 for other villages) in contrast to the student groups ( $p$-value 0.148 ) using the Wilcoxon Matches-Pairs Signed-Ranks Tests. The earnings of the village groups however decline ( $p$-value 0.008 for forestry groups, and 0.022 for other villages) in contrast to student groups (p-value 0.461 ) using the Wilcoxon Matched-Pairs Signed-Ranks Tests. Villagers leave many trees on the board (Figure 5). However, both student groups and village groups lose considerable earnings from penalty payments (Figure 5).

Therefore, in rounds 11-20 we see therefore differences between the types of groups. The villagers have similar level of resource size ( $\mathrm{p}$-value 0.490 ), but the earnings of the forestry groups are significant lower than the groups from other villages ( $p$-value 0.038 ), because they leave more trees unextracted. The student groups have significant less trees left than the village groups (p-value 0.065 with forestry village and 0.081 with other villages). However, the earnings of the students is not significantly different than the village groups (p-value 0.0279 with forestry village and 0.833 with other villages). The reason, however, is because their extraction 
paths start with higher levels of extraction in the first rounds, impeding the regrowth of the resource for subsequent rounds. Further, student groups do not change their behavior significantly after the rule choice, while the villagers reduce the harvesting rate.

We will now look in more detail at how the different rules affect decision making. From Table 3 we saw that students are more likely to vote for quotas. Decisions group members who voted for a certain rule are compared with the decisions they made before the rule change. This is done only for rounds with 25 or more trees, such that participants have the option to harvest 0 to 5 trees. We see in Table 4 that groups who voted for the rotation rule had a significant reduction in the harvesting rate, while the other two rules showed no statistical difference.

Table 3 shows that the level of rule breaking in rounds 11-20 is high. More than half of the time a person harvested more than allowed. The fraction of rule breaking is high from the first round after the elections onwards until the end of the experiment (Figure 7). This indicates that there is a persistent level of noncompliance independent of the remaining level of the resource.

The degree of rule breaking is especially acute for villagers from Colombia. Figure 8 shows that there is a positive relation between those groups who have a high level of rule breaking and the average trust level group members have in the community. This observation is confirmed in a statistical analysis at the group level (Table 5) and the individual level (Table 6). Colombian villagers with higher trust in other community members break the rules more frequently. This relation is not found for either Thai participants or for students. Furthermore, we do not find that forestry groups make different decisions than other groups. Hence being a forestry group does not make them more likely to obey rules or not. We also tested the effect of support for the elected rule. Will groups where all participants voted in favor of the elected rule be less eager to break rules than groups where the elected rule has less support? We do not find any significant evidence for this at the group or individual level.

\section{Discussion}

What explains the differences in the level of rule breaking between the different communities? Although participants could vote for one of the three proposed rules, these rules were seen as coming from external agencies. In understanding the lack of compliance, we make use of complementary investigations in the villages a year after the experiments were performed. We went back to the villages to give them feedback on the experiments and the results, and proposed to them an opportunity to modify the game to introduce some realism. This was a way to assess what type of context players had in mind when they did the experiments. In each village we crafted a game corresponding to their context (crafting an irrigation game in the irrigation village, a fishery game in the fishery village and a forestry game in the forestry village).

Several lessons from the games are relevant for the interpretation of the forestry experiments. In the forestry village in Colombia, villagers are more autonomous in governing their commonly shared territory, given that this village is located in a collectively titled land. They are accustomed to crafting their own local rules. With regard to external rules, villagers see it as acceptable behaviour to follow only the local rules. There is no effective social or pecuniary sanction for brakeing external rules. The more trust there is among villagers, the less social pressure there is to follow these external rules, and the more confidence to break the rules. This could explain why we find a correlation between the stated inter-personal trust and the level of rule breaking. It may seem that these groups interpreted the rules we implemented in the game, not as theirs, but as externally enforced by an authority. The higher levels of trust could imply, therefore, a license to other group members to break such rules because of their weaker legitimacy.

An interesting phenomena from the field work during the first and second visits is related to the role of the sawmill owners who, with oligopolistic power, purchase the timber extracted by numerous individual loggers such as those who participated in our experiments. The sawmill owners play the role of the main middleman in the supply chain of timber. Loggers are strongly dependent on sawmills' demand, who in turn, depend on the regional and national timber demand. Through this mechanism the middlemen drive forest extraction and ultimately could be shaping the ecological conditions of the forest. In general their market power makes them price setters, responding to the demand of the next step in the supply chain. These sawmill owners at times will attempt to enforce certain rules about the size of the timber logs, although they are poorly regulated 
by the market and the authorities, which are mostly absent in the region. We did not find that these middlemen had any interest or impact in creating incentives for a more sustainable rate of extraction of these forests.

In the Colombian irrigation case the local aqueduct has been built and managed endogenously as are many others in the rural areas of this country. Villagers self-organized to obtain resources and construct the aqueduct as a consequence of a severe drought 20 years ago. The implication of this situation combined with the historical and cultural characteristics of the inhabitants of this region have produced a particular behavioral relation with external institutions. Usually there is a gap between behavior and discourse, and also low levels of trust among the community, and even lower toward external actors. Interviewees and participants in the role playing game talked often about the selfishness of this community and also how the rules in the experiments were seen as externally imposed, even if players were asked to vote for the rule to be applied in the experiment. Rule compliance is a function of its legitimacy, which in turn is built endogenously based on the efforts of the community.

The high level of rule breaking in the Colombian fishery village ( $83 \%$ ) could be related to two factors: rule legitimacy and household needs satisfaction. The context analysis showed the relevance of the participation of locals in the construction of rules, especially regarding the National Park authorities, which, in this case, regulated the fisheries in the conservation area. When environmental authorities do not consult fishermen about rules, this renders the legitimacy of these rules low and in turn increases the level of rule breaking. On the other hand, the rule game provided some clues on the high weight local fishermen give to the fulfillment of household needs. The breaking of formal rules is usually justified by convenience or necessity.

In Thailand there was one village which had much higher rule breaking rate than other Thai groups, namely the fishery village. The fishery village members are very individualistic in sharing the resource (Castillo et al., 2011). Each one will harvest the maximum because they have in mind that their neighbor will take the maximum and will not leave anything for them. They are very resistant to public regulation and do not trust the government rules. This may explain why they are the ones who break the rules in the forestry experiment (Table 3). Surprisingly, they have a higher trust index, but they may trust other fellow villagers to not socially sanction them for breaking the external rules.

On the other hand, the forestry and fishery villages experienced low levels of rule breaking. In the forestry village, villagers acted in the past as employees of a logging company, but did not exploit the forest by themselves. Presently, cutting trees is prohibited in the forest and this rule is followed. This is a national rule which is respected by all farmers in Thailand. The consequence is that the experiment is not really about the trees but about the renewable resources they exploit in the forest. In the forestry village they considered that the experiment is similar to the harvest of bamboo trees.

In reality there is not really a scarcity of the resource: bamboos are highly renewable and not overharvested. . Like in Colombia, the harvesting of the bamboo is driven by a trader demand which not exceeding the bamboo natural production. This may explain why, when the players living in a forestry village do the experiments, they do not all behave as selfish rational actors. In the redesign of the experiment, the villagers talked about a sanction in case someone takes more than the allowed quantity.

In the irrigation village rule breaking was not as high as the fishery village but it was similar to the forest village. The farmer's irrigation system is provided by the government, and they can extract as much as they want in their actual irrigation system. Furthermore, farmers share water with their neighbours. During the return visit we learned that farmers negotiate with local government agencies on irrigation management.

In both countries the student groups did not have high rule breaking rates. A possible explanation is that the rules proposed by the experimenters are not seen as externally imposed rules. Furthermore, the students have not had the same experience with external regulations on resource use and may not express dissent based on past experiences. All in all, the information from the return visits teach us that the behaviour of the players is very much context dependent. It depends on the history of the social group, the relationship they have with a given resource, the relationship among members of the group and with the external forces such as external regulations.

It also teach us that the question of the relation between trust and rule-compliance, which is considered as a fundamental one in the field of CPR (Ostrom, 1990), should be carefully investigated. After these experiments and the associated investigations we propose to differentiate two types of trust, a general trust and a 
specific trust. The general trust is related to the level of trust people have in their community, in their network. Do people trust the other? The specific trust is related to a given action situation: do people trust the other members of this situation that they will follow the rules? The difference between these two types of trust can explain counter-intuitive results as we obtain here. People may have a general trust but not a specific trust that people will follow a given set of rules. We may even consider that a trustful group will trust that the members of the group will not follow a given set of rules on resource management.

In the villages of this project two extremes can be distinguished depending on the aversion on external rules and the specific trust they have on others. In the first one, villagers may have strong objections to external regulations and do not follow them in real life and trust other villagers to do the same. At the opposite, people do not have a strong averse reaction to external regulation and follow the elected rules because there is a general and specific trust that others will also follow the rules.

\section{Conclusions}

In this paper we reported on field experiments on forestry resources in Colombia and Thailand. The first ten rounds of the experiments showed that Thai groups have higher earnings than Colombian groups. In most groups the common resource was depleted by or before the end of the ten rounds, but not as rapidly as the model of a self-oriented and income maximizing model would suggest. We did not find a statistical difference in the decisions made by our participants with forestry or resource management experience, although the sign of the effect was as expected, with villages with forestry activities showing a slight reduction in the propensity to break the rules.

In the second set of ten rounds, after participants voted for one of three possible rules (lottery, rotation, quota), groups harvested less from the common resource, but broke the rules quite frequently, for the level (probability) of monitoring of 1/6 (especially villagers in Colombia, who broke the rules when they had higher levels of trust in other community members, which might seem contrary to intuition). However, together with the information collected during the return trips where interviews and role games were conducted, this apparent contradiction indicates that these villagers saw the elected rules as externally imposed regulations which are socially acceptable to be ignored within the community.

Our results on the high levels of rule breaking do not suggest an example of crowding-out of cooperative behavior, though. Instead, the data suggest that a fraction of individuals were not interested in complying with the rule from the beginning and decided to face the stochastic enforcement mechanism. Other studies using similar common-pool resource experiments with imperfect monitoring have also shown steady levels of noncompliance over time (Rodriguez et.al, 2008; Cardenas, 2004), although these comparisons must be made with caution as our experiments has also a dynamic stock process that was not included in the other studies.

The outcomes of the experiments show the importance of the social context of the community of resource appropriators (Poteete et al., 2010) and how social norms interact with externally imposed regulations (Cardenas, 2011). Particular conditions of the resource users and their institutional contexts may explain, as discussed before, the differences between the two countries. However, experience with specific resource management and specific regulations does not lead to differences in the decisions, but expectations about other community members and outsiders do. This shows the importance of how regulations are implemented and how their effectiveness is the result of interactions between social norms and rule enforcement, sometimes acting as complements, other times as substitutes.

Thanks to the additional work conducted in the field with interviews, surveys, and role games we believe that the greater context, beyond the particular individual, the particular session, and even the village, might be playing an important role in how the rules we tested in the experiment were interpreted. Different interpretations may have emerged out of the two contexts due to much more general social norms about the role of rules to guide the normative behavior of individuals. When the experiments were conducted in 2007 , Thailand ranked $84^{\text {th }}$ in the world tables for corruption perception index, twenty places better than Colombia (Transparency International, 2012). Using the World Values Survey (Colombia 2005 and Thailand 2007) online databases (http:// www.wvsevsdb.com/) one can find that Colombian people are more likely to agree with the sentence "Competition is good" and more Thai people agree with "Competition is harmful." Likewise, Thai people align more with the sentence "People should take more responsibility" and Colombians leaning more 
toward "The government should take more responsibility." To the question on how much respondents are confident in the civil service or the justice system, one can find that many more Thai respond positively than the Colombians. In terms of trust, one can find a clear difference between the two societies, with more Thais trusting their neighborhoods, trusting people they meet for the first time and most people in general ${ }^{1}$.

Nations and societies build norms that interact with regulations. Other experimental studies using crosscountry samples have also found how national based norms may explain behavior. For instance Hermann et al. (2008) find, using 16 comparable subject pools in different countries, that the national levels of civic norms and rule of law explains individuals' willingness to punish behavior by others that goes against the group benefit. How individuals interpret and evaluate the costs and benefits of complying or violating rules should be analyzed through the lens of social norms. Our experimental design had the same material conditions for the two samples of villagers in terms of the benefits of leaving resource units in the ground for future use and the benefits of extracting them, as well as the same material implications of imposing the different rules offered to the participants. Yet, we find differences across the two samples, which might be consistent with the field observation and other national secondary data regarding the social norms that also govern behavior and rule compliance.

\section{Acknowledgements}

We would like to acknowledge the support provided by the National Science Foundation (BCS-0432894) as well as our appreciation for comments on an earlier version of this manuscript by Elinor Ostrom and editing support by Jennifer Fraser.

\section{References}

Anderies, J.M., M. A. Janssen, F. Bousquet, J-C. Cardenas, D. Castillo, M-C. Lopez, R. Tobias, B. Vollan, A. Wutich (2011) The challenge of understanding decisions in experimental studies of common pool resource governance, Ecological Economics 70 (9): 1571-1579.

Cárdenas, J. C., J. K. Stranlund and C. E. Willis. 2000 Local environmental control and institutional crowding out. World Development. 28(10): 1719-1733.

Cardenas, J.C. 2001. Social norms and behavior in the local commons as seen through the lens of field experiments. Environmental and Resource Economics 48(3): 451-485.

Cardenas, J.C.(2004) Norms from Outside and from Inside: An Experimental Analysis on the Governance of Local Ecosystems. Forest Policy and Economics, 6: 229-241. Elsevier Press

Castillo, D., F. Bousquet, M.A. Janssen, K. Worrapimphong, and J-C. Cardenas (2011) Context matters to explain field experiments: results from Thai and Colombian fishing villages, Ecological Economics 70(9): 1609-1620.

Ghate, R., S. Ghate, and E. Ostrom (2011) Indigenous Communities, Cooperation, and Communication: Taking Experiments to the Field. SANDEE Working Paper, No $64-11$.

Herrmann, B., C. Thöni, S. Gächter 2008. Antisocial punishment across societies Science 319: 1362-1367

Kluvánková-Oravská, T. (2011) Can long lasting forest institution survive market economy? The case of

historical common property forest regime in Slovakia, unpublished manuscript.

Ostrom, E. (1990) Governing the Commons, Cambridge University Press.

Poteete, A.R., Janssen, M.A., Ostrom, E.(2010) Working Together - Collective Action, the Commons, and

Multiple Methods in Practice. Princeton University Press.

Rodríguez-Sickert, C., R.A. Guzmán , J.C. Cárdenas (2008) Institutions influence preferences: evidence from a common pool resource experiment, Journal of Economic Behavior and Organization 67(1): 215-227.

Titmuss, R.M., 1970. The Gift Relationship: From Human Blood to Social Policy. George Allen and Unwin, London.

${ }^{1}$ In other questions on trusting the government, from the same World Values Survey the results were mixed. 
Transparency International (2012). Corruption perception index, downloaded from

http://www.transparency.org/policy_research/surveys_indices/cpi/2007 [January 23, 2012)

Vollan, B. (2008) Socio-ecological explanations for crowding-out effects from economic field experiments in southern Africa, Ecological Economics 67: 560-573. 
Table 1: Maximum harvest table

\begin{tabular}{cc} 
Current Resource Level & Individual Maximum harvest level \\
\hline $25-100$ & 5 \\
$20-24$ & 4 \\
$15-19$ & 3 \\
$10-14$ & 2 \\
$5-9$ & 1 \\
$0-4$ & 0 \\
\hline
\end{tabular}

Table 2. Social-economic factors

Colombia

Thailand

\begin{tabular}{|c|c|c|c|c|c|c|c|c|}
\hline & $\begin{array}{l}\text { Fishery } \\
\text { village }\end{array}$ & $\begin{array}{l}\text { Forestry } \\
\text { village }\end{array}$ & $\begin{array}{l}\text { Irrigation } \\
\text { village }\end{array}$ & $\begin{array}{l}\text { Students } \\
\text { Bogota }\end{array}$ & $\begin{array}{l}\text { Fishery } \\
\text { village }\end{array}$ & $\begin{array}{l}\text { Forestry } \\
\text { village }\end{array}$ & $\begin{array}{l}\text { Irrigation } \\
\text { village }\end{array}$ & $\begin{array}{l}\text { Students } \\
\text { Bangkok }\end{array}$ \\
\hline Age & 40.5 & 47.8 & 36.3 & 20.3 & 44.7 & 39.1 & 31.2 & 19.0 \\
\hline Male & $100 \%$ & $95 \%$ & $55 \%$ & $65 \%$ & $55 \%$ & $55 \%$ & $70 \%$ & $40 \%$ \\
\hline Married & $80 \%$ & $80 \%$ & $80 \%$ & $0 \%$ & $80 \%$ & $70 \%$ & $65 \%$ & $0 \%$ \\
\hline Education ${ }^{1}$ & 1.7 & 0.8 & 1.9 & 4.3 & 3.3 & 3.4 & 3.7 & 6 \\
\hline Trust $^{2}$ & 0.57 & 0.57 & 0.48 & 0.66 & 0.69 & 0.63 & 0.64 & 0.58 \\
\hline
\end{tabular}

${ }^{1}$ What is the highest grade you have completed in school? 0 None; 1 Some primary school; 3 Primary school; 4 Secondary school; 5 Technical; 6 University;

Table 3. Results of experiments

$$
\text { Colombia }
$$

Thailand

\begin{tabular}{|c|c|c|c|c|c|c|c|c|}
\hline & $\begin{array}{l}\text { Fishery } \\
\text { village }\end{array}$ & $\begin{array}{l}\text { Forestry } \\
\text { village }\end{array}$ & $\begin{array}{l}\text { Irrigation } \\
\text { village }\end{array}$ & $\begin{array}{l}\text { Students } \\
\text { Bogota }\end{array}$ & $\begin{array}{l}\text { Fishery } \\
\text { village }\end{array}$ & $\begin{array}{l}\text { Forestry } \\
\text { village }\end{array}$ & $\begin{array}{l}\text { Irrigation } \\
\text { village }\end{array}$ & $\begin{array}{l}\text { Students } \\
\text { Bangkok }\end{array}$ \\
\hline $\begin{array}{l}\text { Trees } \\
\text { Rounds } 1- \\
10\end{array}$ & 41.0 & 38.3 & 29.4 & 24.5 & 36.7 & 35.2 & 36.0 & 39.6 \\
\hline $\begin{array}{l}\text { Trees } \\
\text { Rounds 11- } \\
20\end{array}$ & 46.1 & 55.1 & 43.3 & 40.9 & 55.5 & 61.0 & 60.2 & 40.6 \\
\hline Lottery & 1 & 1 & 0 & 0 & 1 & 0 & 1 & 1 \\
\hline Rotation & 3 & 3 & 4 & 2 & 3 & 3 & 3 & 0 \\
\hline Quota & 0 & 0 & 0 & 2 & 0 & 1 & 0 & 3 \\
\hline $\begin{array}{l}\text { Rule } \\
\text { breaking }\end{array}$ & $83 \%$ & $80 \%$ & $70 \%$ & $49 \%$ & $65 \%$ & $43 \%$ & $48 \%$ & $44 \%$ \\
\hline
\end{tabular}


Table 4: The average extraction level over 10 rounds before and after the rule change for three types of elected rules. The fifth row is a test whether the distributions of extraction decisions statistically differ.

\begin{tabular}{llll} 
& Lottery & Rotation & Quota \\
\hline Extraction rate rounds 1:10 & 3.04 & 3.46 & 3.60 \\
Extraction rate 11:20 & 3.04 & 2.94 & 3.21 \\
\# groups & 5 & 21 & 6 \\
Wilcoxon Matched-Pairs & p-value $=0.813$ & p-value $<0.001$ & p-value $=0.438$ \\
Signed-Ranks Tests & & & \\
\hline
\end{tabular}

Table 5: A regression analysis is performed with the relative frequency of rule breaking. The independent variables are the country (Colombia $=0$; Thailand $=1$ ), dummies for forestry dominated villages and student groups, average trust, and the share of the elected rule during the first voting round, which indicates the level of commitment to the elected rule.

\begin{tabular}{|c|c|c|c|}
\hline & $\begin{array}{l}\text { Fraction } \\
\text { breaking }\end{array}$ & $\begin{array}{l}\text { Fraction } \\
\text { breaking } \\
\text { Colombia }\end{array}$ & $\begin{array}{l}\text { Fraction } \\
\text { breaking } \\
\text { Thailand }\end{array}$ \\
\hline Constant & $0.542(0.219)$ & $-0.135(0.132)$ & $0.207(0.518)$ \\
\hline Thailand $(=1)$ & $-0.211 * * *(0.059)$ & & \\
\hline Forestry village & $-0.023(0.069)$ & $0.017(0.043)$ & $-0.058(0.108)$ \\
\hline Student & $-0.207 * *(0.070)$ & $-0.410 * * *(0.048)$ & $-0.054(0.127)$ \\
\hline Trust & $0.368(0.318)$ & $0.979 * * *(0.195)$ & $0.685(0.829)$ \\
\hline $\begin{array}{l}\text { Share voted for elected } \\
\text { rule }\end{array}$ & $0.019(0.205)$ & $0.174(0.123)$ & $-0.154(0.384)$ \\
\hline $\mathrm{N}$ & 32 & 16 & 16 \\
\hline -Log Likelihood & 15.520 & 21.516 & 5.708 \\
\hline Wald $\chi 2$ & $21.64(p=0.001)$ & $95.17(p=0.000)$ & $2.07(p=0.723)$ \\
\hline
\end{tabular}


Table 6: A regression analysis is performed with the relative frequency of rule breaking. Separate regressions are performed for Colombia and Thailand. The independent variables include dummies for forestry dominated villages and student groups, trust, and a dummy whether the participant did not vote $(=1)$ for the rule.

\begin{tabular}{|c|c|c|}
\hline & $\begin{array}{l}\text { Fraction rule breaking } \\
\text { Colombia }\end{array}$ & $\begin{array}{l}\text { Fraction rule breaking } \\
\text { Thailand }\end{array}$ \\
\hline Constant & $0.298 * *(0.123)$ & $0.734 * * *(0.200)$ \\
\hline Forestry village & $-0.002(0.076)$ & $-0.088(0.108)$ \\
\hline Student & $-0.406 * * *(0.081)$ & $-0.139(0.111)$ \\
\hline Trust & $0.909 * * *(0.213)$ & $-0.272(0.273)$ \\
\hline Voted different & $-0.029(0.064)$ & $0.042(0.077)$ \\
\hline $\mathrm{N}$ & 80 & 80 \\
\hline -Log Likelihood & 10.193 & 26.051 \\
\hline Wald $\chi^{2}$ & $36.14(\mathrm{p}=0.000)$ & $2.87(\mathrm{p}=0.581)$ \\
\hline
\end{tabular}


Figure 1: Resource size patterns for non-cooperative and cooperative equilibria.

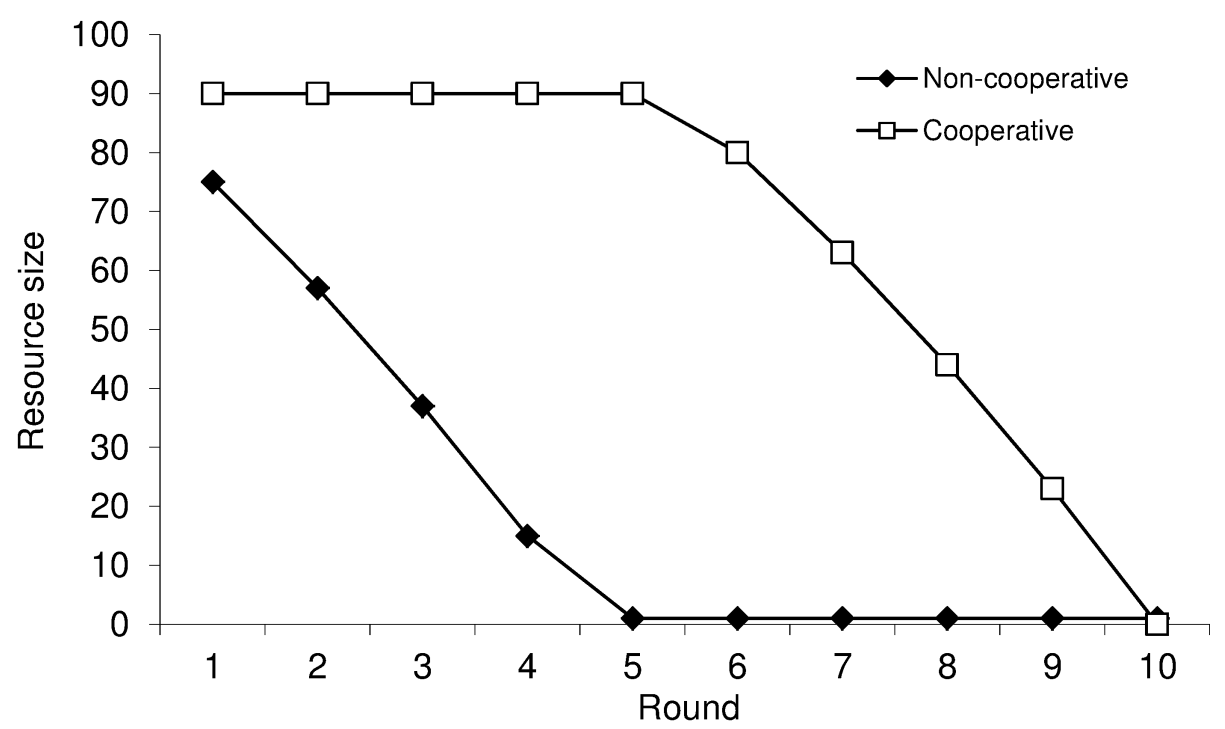


Figure 2: Resource size patterns for non-cooperative equilibrium and for the cases the rules are followed.

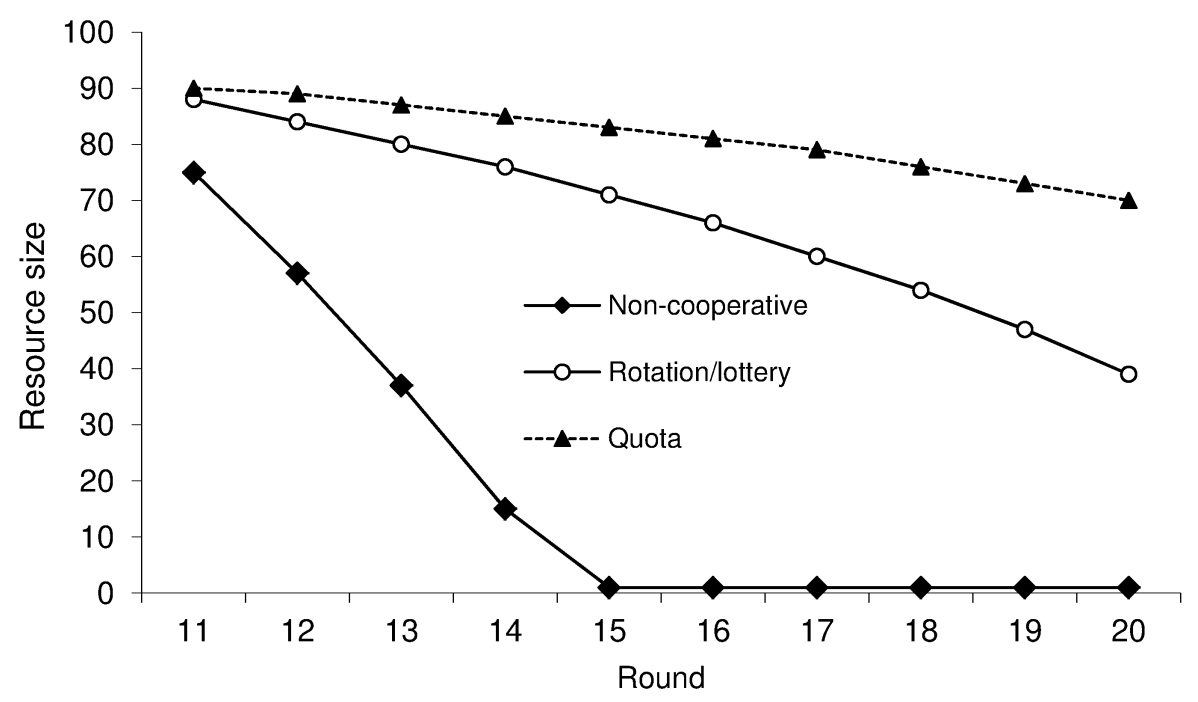


Figure 3: Average resource size for all 32 groups for rounds 1-10 (stage 1) and rounds 11-20 (stage 2).

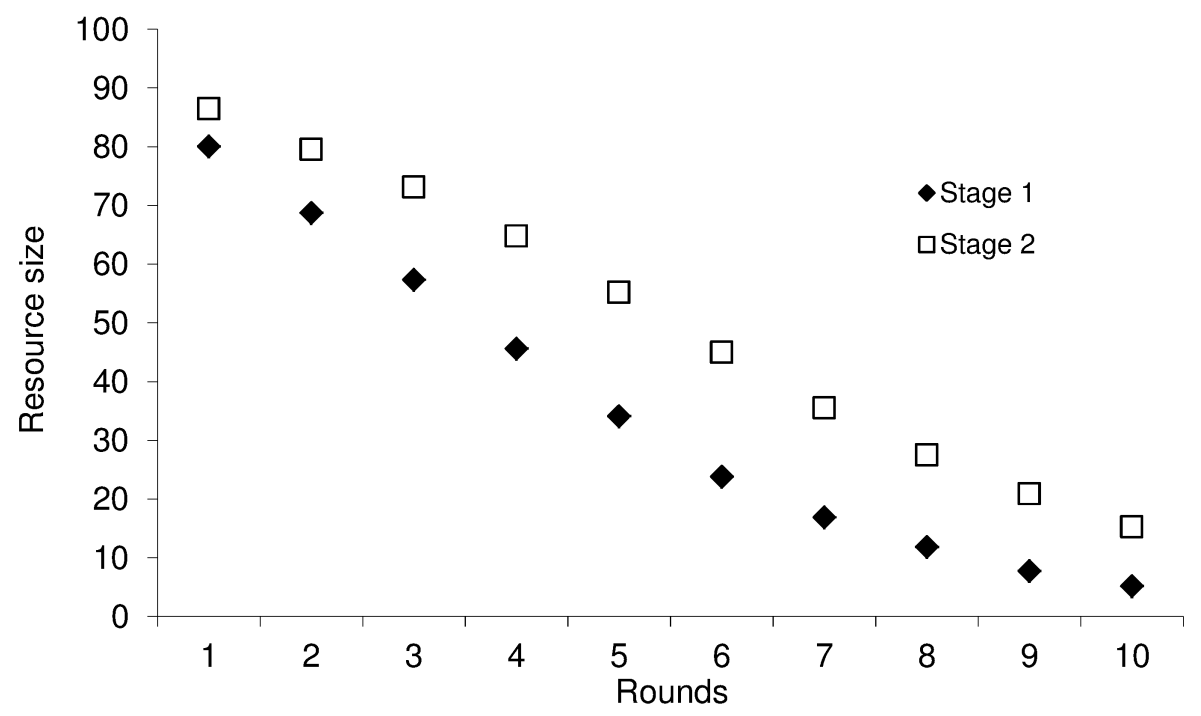


Figure 4: For each group the earnings accumulated over the rounds 1 to 10 are depicted as well as the number of trees remaining after round 10 (forgone earnings).

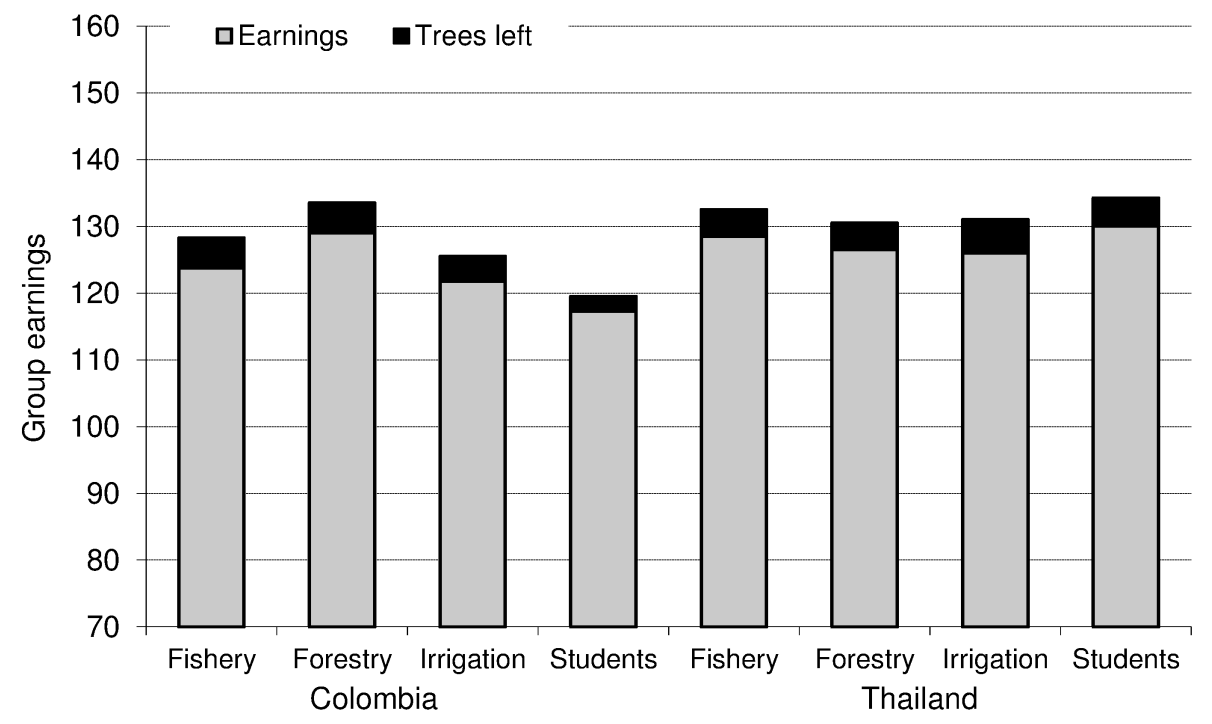


Figure 5: Depicted for each village are the earnings accumulated over rounds 11-20, the number of trees remaining after round 20 (forgone earnings), and the number of tokens paid as penalties for breaking rules.

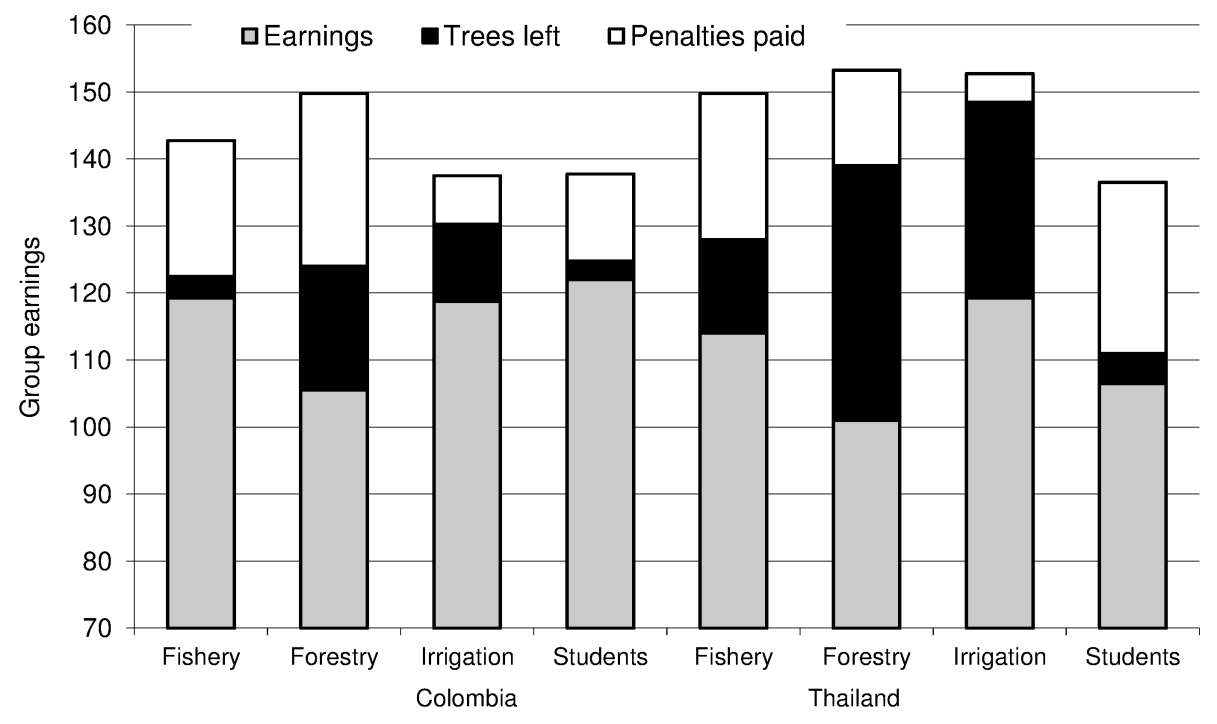


Figure 6: Depicted for each rule elected are the earnings accumulated over the rounds 11 to 20, the number of trees remaining after round 20 (forgone earnings), and the number of tokens paid as penalties for breaking rules. 


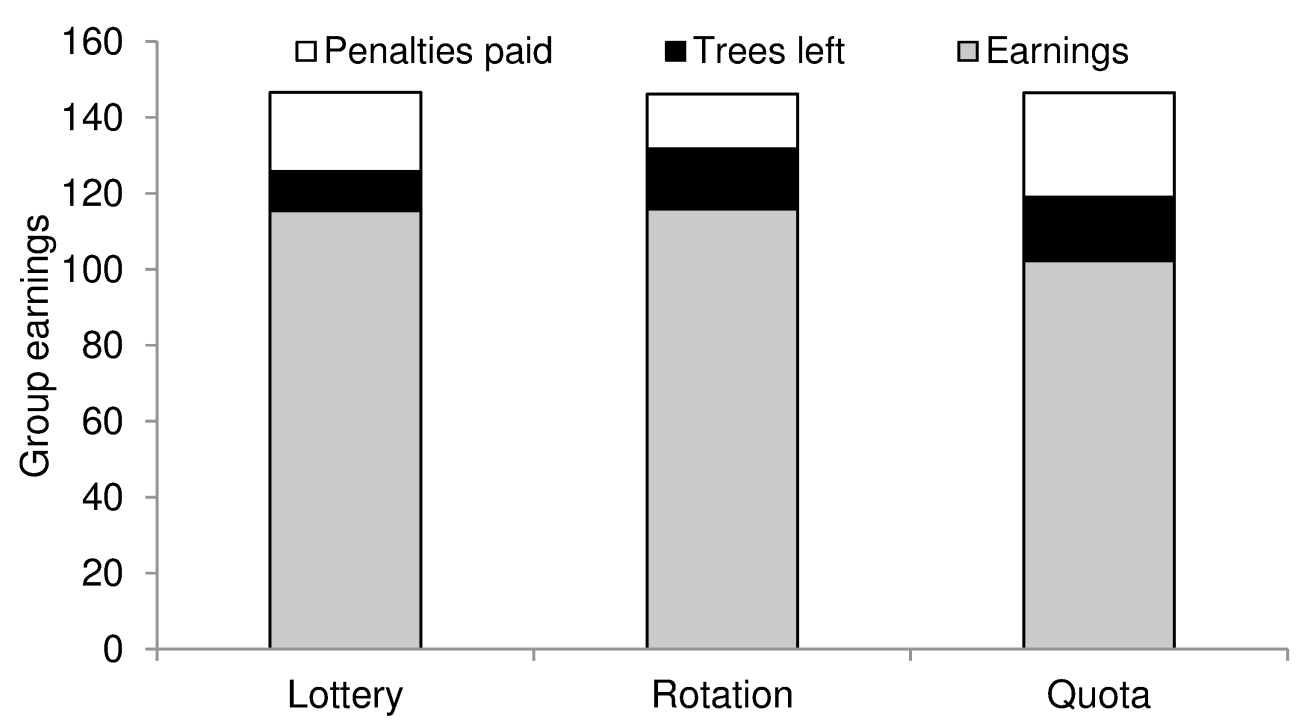


Figure 7. The fraction of rule breaking over the rounds.

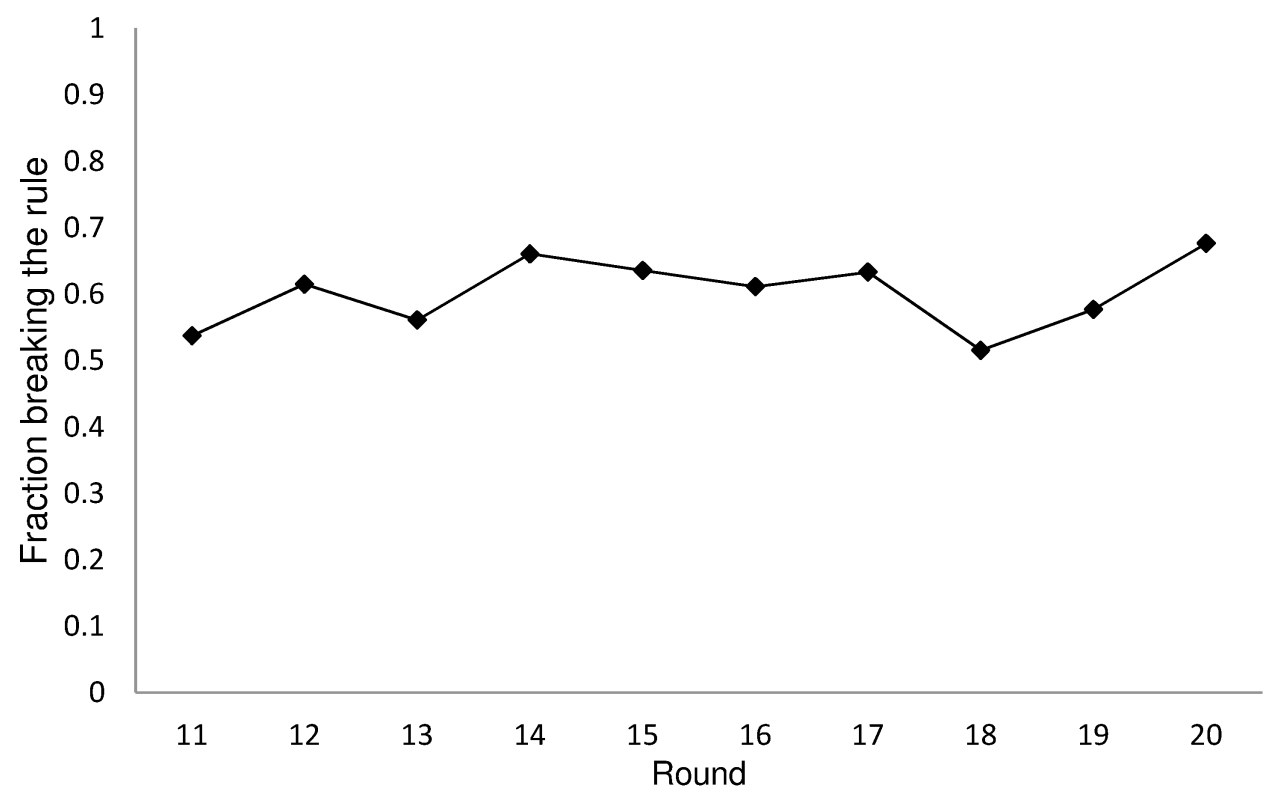


Figure 8: Relation between fraction of the time individuals in groups break the rule versus the average trust group members have in the community.

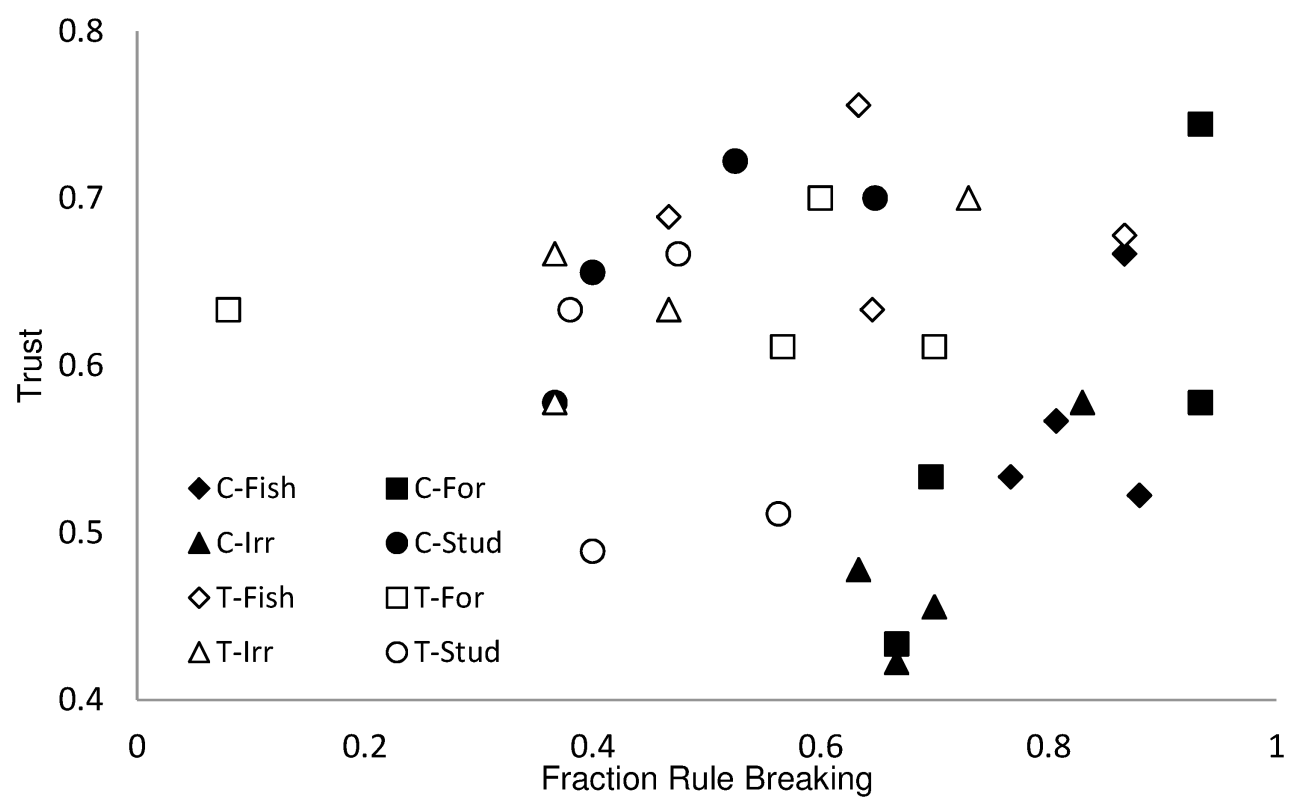




\section{Appendix}

\section{INSTRUCTIONS FOR THE FORESTRY GAME}

Below are the instructions and the material used to perform the experiment. The material is in English while the actual experiments are run in Thai and Spanish.

\section{FIRST STAGE}

We would like to thank you for accepting this invitation. We will spend about two hours explaining the activity, playing and answering a short survey at the end. Let's start.

The following exercise is a different and entertaining way to actively participate in a project about individual decisions and natural resources. Besides participating in this exercise and earning money, you will participate in a workshop in the coming days in order to jointly discuss the exercise as well other topics about natural resources. The funds to cover these expenses have been donated by a scientific body.

In this exercise it is intended to recreate a situation in which a group or family must make decisions about the use of a forest. You have been selected to participate in a five person group recruited from a group of people who have been subscribed to be willing to participate.

This exercise is different than experiments in which other persons in this community have played already. Therefore, comments you have heard from other persons do not apply necessarily to this exercise.

You will play several rounds equivalent, for example, to years or wood harvest seasons.

Let's pretend this group has an area of forest with 100 initial resource units. Each round you have to make a decision about how many resource units you want to harvest. You can harvest a maximum of 5 units and minimum of 0 units of the resource.

[Visual explanation; we have a number of magnets on the board which represent the forest units. The instructor shows what happens if a number of units are harvested]

Between the rounds the resource is regrowing. For each ten units of the existing resource, one new unit is added for the next round. [visual explanation; the monitor shows with the magnets that for each row of 10 magnets one new magnet is added to the forest, use rows of 10 magnets on the board]. The forest can not grow to more than 100 units.

Each participant makes a harvest decision. Each harvest unit is equivalent to $\$ 200$ pesos. For example, if you harvest 100 units during 20 rounds you will receive $\$ 20.000$ pesos.

When the size of the resource is less than 25 units, the maximum harvest is less than 5 units.

In the MAXIMUM HARVEST LEVEL TABLE, that is green, which will be distributed now [MONITOR distributes the MAXIMUM HARVEST LEVEL TABLE at the same time he shows a poster on the wall of the same table]. I will announce the maximum quantity of units you can harvest according to the size of the resource at the beginning of the round and post it on the wall.

In order to make decisions in each round you must write down your decision on your YELLOW DECISION SHEET, a number between 0 and the MAXIMUM HARVEST LEVEL depending on the current resource level. [MONITOR shows the yellow decision sheet at the same time that shows a poster on the wall with the same card]. Please check your player number on the yellow decision sheet. This will be your player number from now on. 
Observe that the sheet has a row with the round number. Next there is a row marked with "my harvest decision", in this space you will write down the harvest level you decided in this round.

It is very important to know that you must make your decisions privately. Therefore, you need to write down the numbers on the decision sheet in private and you can not show them to the rest of the group members. The MONITOR will collect the YELLOW DECISION SHEETS from all of you and she or he will sum the total of units the group decided to harvest. When the monitor announces the group harvest total I will write on the board the new resource level. You will then get the decision sheets back for the next round.

Let us explain this with an example (Use visual explanation).

Suppose the current size of the resource is 68 . Each of you decided to harvest 3 units, and thus a total of 15 units. The resource size reduces to $53(68-15)$ and then $10 \%$ of 53, which is 5 units, is added, which leads to 58 units. Thus 15 units are harvested, and the size of the resource, after regrowth, is reduced with 10 units. And each participant earned 3 points during this round.

For each 10 units of resource 1 unit is added. If there are no 10 units of resource we do not increase the resource, it means if there are less than 10 units we do not add 1 unit more. If the resource is less than 5 units, no units can be harvested any more. Now let's continue with the next round. Now the current size of the resource is 58 units. It means that the maximum harvest allowed remains 10 units according to the MAXIMUM HARVEST LEVEL TABLE.

Again, each player decides how many units to harvest and again we calculate the resource decreasing and its increase in a $10 \%$ for new level of the resource.

Now we are going to explain the PLAYER CALCULATION SHEET, the white sheet the MONITOR has handed in to you.

[Before we start the monitor will announce one additional rule for this group.]

To start the first round of the game we will organize the seats and desks in a circle where each of you face outwards. The monitor will collect in each round your YELLOW DECISION SHEET. Finally, to get ready to play the game, please let us know if you have difficulties reading or writing numbers and one of the monitors will seat next to you to assist you with these. Also keep in mind that from now on no conversation or statements should be made by you during the game unless you are allowed to.

We will have first a few rounds of practice that will NOT count for the real earnings, just for practicing of the game.

[up to three practice rounds are performed and questions are addressed during the practice]

The initial size of the resource is 100 units

[After the practice rounds announce that the initial size of the resource is again 100 units and that the decisions are now real and affect the earnings]

\section{INSTRUCTIONS FOR THE FOREST GAME SECOND STAGE}

[After 10 real rounds we let the participants vote for one of three rules.] 
We give you the opportunity to start over the game with a different rule. I will describe three rules and you write down on your VOTING CARD your favorite rule. The monitor will collect the votes and count them. [If two rules get 2 votes, we do a new voting round with only these to rules]

The rule which derives the most votes will be implemented.

Rule 1. With this rule only two participants can harvest each round. Who is allowed to harvest is determined by drawing two cards with players numbers. The instructor writes down the player numbers who are allowed on the board.

When someone harvest, but is not allowed to, this participant may get a penalty. Every round we throw a dice after the decisions are made and the yellow sheets are turned in. If we throw a six an inspector is in the forest and will catch the rule breakers, the participants who harvested in a turn it was not allowed to. In that case the participant has to payback the harvest plus an extra 3 units. If the dice shows any other number everybody keeps its earnings and we pass to the next round.

Rule 2. With this rule each participant will have its turn to extract forest unit. Only two participants can harvest each round. In this way it will be a rotation scheme to extract forest units. Each participant will be assigned randomly a turn card to extract forest units: The extraction order is:

Round 1: extracts wood the player A, B

Round 2 extracts wood the player $\mathbf{C ,} \mathbf{D}$

Round 3: extracts wood the player $\mathbf{E}, \mathbf{A}$

Round 4: extracts wood the player B, C

Round 5: extracts wood the player $\mathbf{D}, \mathbf{E}$

Round 6: extracts wood the player A, B

Round 7: extracts wood the player $\mathbf{C}, \mathbf{D}$

Round 8 extracts wood the player $\mathbf{E}, \mathbf{A}$

Round 9: extracts wood the player $\mathbf{B}, \mathbf{C}$

Round 10: extracts wood the player D, E

(explain explicitly that after this rule is chosen, players get randomly a character A, B, C, D or E. player 1 may for example get turn D)

When someone harvest, but is not allowed to, this participant may get a penalty. Every round we throw a dice after the decisions are made and the yellow sheets are turned in. If we throw a six an inspector is in the forest and will catch the rule breakers, the participants who harvested in a turn it was not allowed to. In that case the participant has to payback the harvest plus an extra 3 units. So, if participant whose turn is A is writing down on the decision sheet to harvest 3 units when only the player with turn $\mathrm{C}$ is allowed to harvest, we throw a dice, and when we throw a six, participant with turn A do not get the points on its decision sheet, and we subtract an extra 3 from the total collected points of player with turn A. If the dice shows any other number everybody keeps its earnings and we pass to the next round.

Rule 3. Each of you can harvest legally 0, 1 or 2 units per round. If a participant writes a higher amount than 2 on its game card, he or she can be caught by the inspector and has to pay a penalty. In every round we throw a dice. And when we throw a six, and the participants who harvest more than 2 units in that round, do not get the points it wrote down on its game card, and we subtract an extra 3 points from it's total so far.

Rule 1: only 2 persons, randomly determined, allowed to harvest in each round.

Rule 2: only 2 persons, predetermined sequence, allowed to harvest in each round

Rule 3; a maximum of 2 units can be harvested in each round by any person

Do you have any questions about the rules? 
Write down your favorite rule on the VOTING CARD, by writing a 1 , a 2 or a 3 . And turn it in to the monitor 
Forms that will be used to document informed consent and assent (e.g., written consent form, written assent, cover letter).

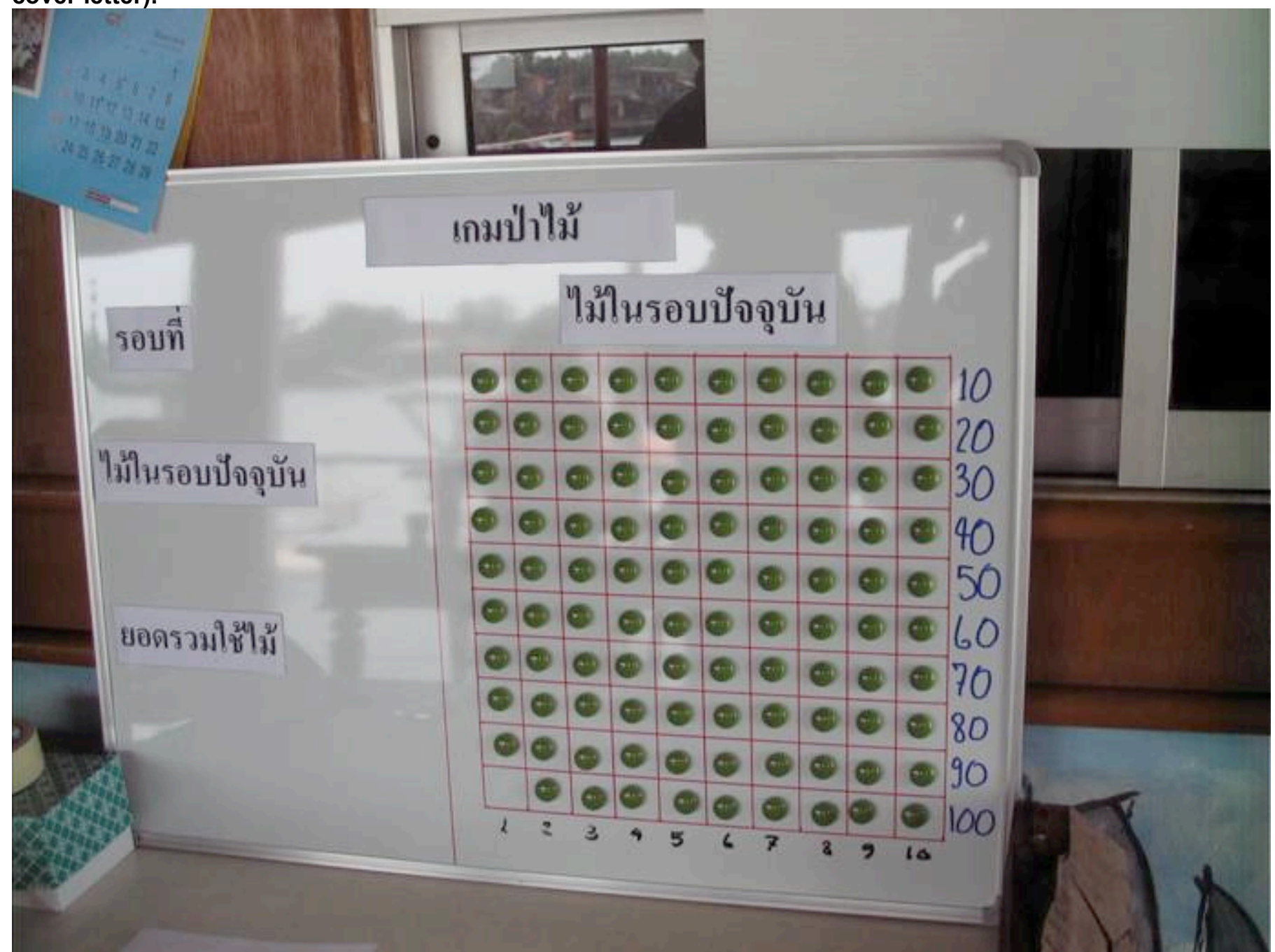

Fig A1. Magnets representing trees during experiments in Thailand. 


\section{INDIVIDUAL SURVEY}

Date $(\mathrm{dd} / \mathrm{mm} / \mathrm{yy})$

Place

Surveyor

Village
/ I

Time

Survey number

EXP Player number 


\section{SECTION I. RESPONDENT CHARACTERISTICS}

1. How old are you? years

2. Sex $\square$ Male $\square$ Female

3. Marital Status
1. Common law
3. Widowed
2. Married
4. Divorced
5. Separated
6. Single

4. What is the highest grade you have completed in school?

YEARS
None
Some primary school
Primary school
Secondary school
Technical
University
Post-university

Level

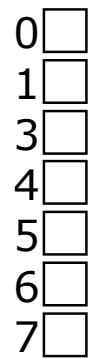

5. How long have you lived in this community?

YEARS

6. What is your main Economic Activity defined as the activity in which you spent the most time during the year? (mark only one)

1. Extracting products from the forests

2. Fishery

3. Farmer

If farmer, do you use irrigation? $\square$ Yes $\square$ No

4. other, which one

7. Average number of hours per week for the marked activity?

hours

8. What is your main Economic Activity defined as the activity in which you received the most income during the year? (mark only one)

1. Extracting products from the forests

2. Fishery

3. Farmer

If farmer, do you use irrigation? $\square$ Yes $\square$ No

4. other, which one

9. Average share of your income for the marked activity? almost nothing of my income little income about one quarter of income about half of income about three quarters 
$\square$ almost all my income 


\section{SECTION II. HOUSEHOLD CHARACTERISTICS}

1. Number of people (adults and children) in your household including yourself

2. How long has your family (ancestors) lived in this community? YEARS

3. Have you or any in your household participated in voluntary work related to managing, conserving, or monitoring the common pool of natural resources in your village during the last year?

$\square$ Yes, how many days per year?

4. The dwelling that this household occupies is:

1. Owned and totally paid for

2. Owned and being paid for

3. Inheritance or gift

4. Right of possession

5. Rented

6. Transferred or loaned

7. Other form

5. Are you or anyone from your household the owner of this land you live in?

$\square$ Yes. How many hectares (acres)?

$\square$ No

\section{SECTION III. COLLECTIVE ACTION}

1. Please tell me whether in general you agree or disagree with the following statements:

Disagree Strongly

Strongly Agree

agree

1. Most people in this village are basically honest and can be trusted.

1. $\square$ 2. $\square$ 3. $\square$ 4. $\square$

2. People in this village are mostly interested in their own well-being

3. Members of this village are always more trustworthy than those in other villages.

4. In this village one has to be alert, or someone will take advantage of you.

1. $\square$ 2. $\square$ 3. $\square 4$.

1. $\square$ 2. $\square$ 3. $\square 4$.

1. $\square$ 2. $\square$ 3. $\square 4$.

5. If I have a problem there is always someone in 
this village to help you.
1.
1. $\square$
2. $\square 3$.
3. $\square 4$.

6 . I do not pay attention to the opinions of others in the village.

1 .

$\square$

2. $\square$

3. $\square$ 4. $\square$

7. Most people in this village are willing to help if you need it.

1. $\square 2$.

3. $\square 4$.

8. This village has prospered in the last five years.

1. $\square 2$.

3. $\square 4$.

9. I feel accepted as a member of this village

10. If you lose a pig or chicken someone in the village would help look for it or would return it to

1. $\square \quad 2$.

3. $\square 4$.

1. $\square 2$.

3. $\square 4$. you.

2. How much influence do you think people like yourself can have in making this village a better place to live?
\begin{tabular}{|l|}
$\square$ \\
\hline$\square$ \\
\hline$\square$ \\
\hline$\square$
\end{tabular}
1. A lot
2. Some
3. Not very much
4. None
5. Don't know/not sure

3. If there was a problem related to natural resource use in this community, how likely is that people will cooperate to try to solve the

problem?
$\square \quad 1$. Very likely
$\square$
$\square$
$\square$
$\square$
2. Somewhat likely
3. Neither likely nor unlikely
4. Somewhat unlikely
5. Very unlikely

4. How often in the past year have you joined others in the village to address a issue related to the use of a common resource, like ?

\section{Fishery Water management}

Forest

1. Never

2. Once

3. A couple of times

4. Frequently
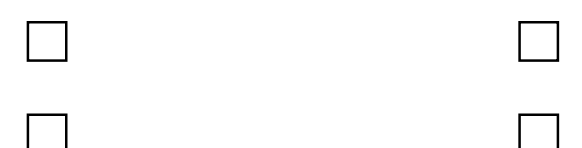

5. Give examples of these activities? 


\section{SECTION IV. QUESTIONS AFTER THE EXERCISES}

1. How satisfied were you with the earnings during the exercises?

1. I was completely dissatisfied

2. I was not satisfied

3. I was somewhat satisfied

4. I was satisfied

5. I was very satisfied

2. Did you understand the instructions of the exercises?

1. I did not understood anything

2. I did understand only a bit of the instructions

3. I did understood half of the instructions

4. I did understood most of the instructions

5. I did understood everything

3. Were you paying attention to the behavior of the other participants? $\square$ yes $\square$ no

4. Were your decisions influenced by behavior of others?

$\square$ yes $\square$ no

5. If you had the chance to return to the start of the $2^{\text {nd }}$ stage, right before we changed the rules of the game to lottery/rotation/property rights, would you have preferred to maintain the rules unchanged and continue playing the same way as in the $1^{\text {st }}$ stage?

$\square$ yes, I would have preferred not changing the rules for the $2^{\text {nd }}$ stage.

$\square$ no, I would have preferred to have the rules changed to the rule we in fact used.

$\square$ no, I would have preferred to have the rules change to another rule (Describe here)

6. Does this exercises represent in a simplified form any experiences you have faced in this village? 


\begin{tabular}{l}
$\square \quad$ 1. Nothing at all \\
$\square \square$ \\
\hline$\square \quad$ 2. A little bit \\
\hline$\square \quad$ 3. More or less \\
\hline$\square \quad$ 5. Yes, in a major way \\
5. Yes, completely
\end{tabular}

Do you have some final remarks on the exercises? You can write them here: 


\section{Interview checklist}

1. What is the role of the individual in the community (leadership, resource extraction, social status, knowledge)?

2. How is the exercises similar and different from real life dilemmas the participants experience? (with a focus on the rules in use)

3. How are rules crafted or changed in this community?

4. What members of the community participate most in solving the problems and conflict resolution in the community related to natural resources?

5. What is the ability of the community to change the rules vs imposed rules? Imposed by whom?

6. Is resource used for self sufficiency or for deriving cash?

7. How well are resources maintained?

8. In the past 12 months, how often have people in this village got together and jointly petitioned government officials or political leaders for something related to natural resource use that would benefit the community?

9. To what extent do local government and local leaders take into account concerns voiced by you or voiced by people like you when they make decisions that affect natural resources?

10. Suppose community members argue that a government imposed rule need to be changed is this possible?

11. If somebody breaks a rule what is the likelihood that this will be detected, and sanctioned?

12. For how long does the community use the resource of interest? What has been the history of governance and resource use?

13. What are the challenges and opportunities for the community in terms of resource use? (globalization, dams, employment opportunities in urban areas) 


\begin{tabular}{|c|c|}
\hline \multicolumn{2}{|c|}{ Maximum harvest table } \\
\hline Current Resource Level & $\begin{array}{c}\text { Individual Maximum } \\
\text { harvest level }\end{array}$ \\
\hline $25-100$ & 5 \\
\hline $20-24$ & 4 \\
\hline $15-19$ & 3 \\
\hline $10-14$ & 2 \\
\hline $5-9$ & 1 \\
\hline $0-4$ & 0 \\
\hline
\end{tabular}




\begin{tabular}{ll|l|l|l|}
$\mathrm{A}$ & $\mathrm{B}$ & $\mathrm{C}$ & $\mathrm{D}$ & $\mathrm{E}$ \\
\hline
\end{tabular}




\begin{tabular}{|l|l|}
\hline \multicolumn{3}{|c|}{ Voting card } \\
\hline Player number & $\mathbf{1}$ \\
\hline $\begin{array}{l}\text { I vote for the rule } \\
\text { number }\end{array}$ & \\
\hline
\end{tabular}

\begin{tabular}{|l|l|}
\hline \multicolumn{3}{|c|}{ Voting card } \\
\hline Player number & $\mathbf{1}$ \\
\hline $\begin{array}{l}\text { I vote for the rule } \\
\text { number }\end{array}$ & \\
\hline
\end{tabular}

\begin{tabular}{|l|l|}
\hline Voting card \\
\hline Player number & $\mathbf{2}$ \\
\hline $\begin{array}{l}\text { I vote for the rule } \\
\text { number }\end{array}$ & \\
\hline
\end{tabular}

Voting card

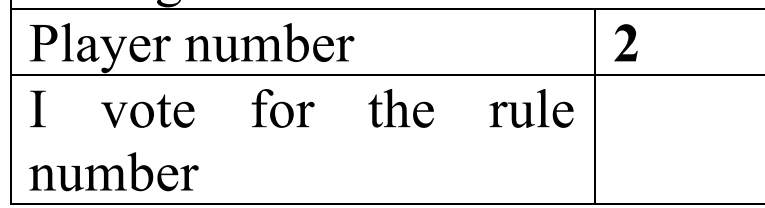

\section{Voting card}

\begin{tabular}{|l|l|}
\hline Player number & $\mathbf{3}$ \\
\hline $\begin{array}{l}\text { I vote for the rule } \\
\text { number }\end{array}$ & \\
\hline
\end{tabular}

Voting card

\begin{tabular}{|l|l|}
\hline \multicolumn{3}{|c|}{ Voting card } \\
\hline Player number & $\mathbf{4}$ \\
\hline $\begin{array}{l}\text { I vote for the rule } \\
\text { number }\end{array}$ & \\
\hline
\end{tabular}

Voting card

Player number

I vote for the rule number

\section{Voting card}

\begin{tabular}{|l|l|}
\hline Player number & $\mathbf{3}$ \\
\hline $\begin{array}{l}\text { I vote for the rule } \\
\text { number }\end{array}$ & \\
\hline
\end{tabular}

\section{Voting card}

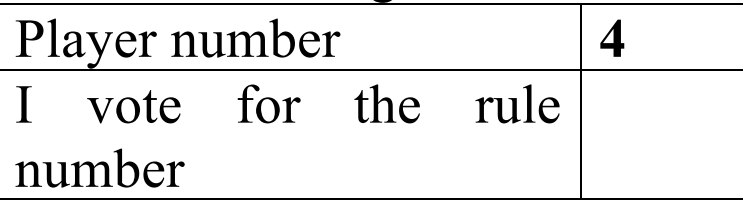

\section{Voting card}

Player number

I vote for the rule number 


\begin{tabular}{|c|c|}
\hline $\begin{array}{l}\text { Player calc } \\
\text { Player no: }\end{array}$ & $\begin{array}{l}\text { sheet } \\
\text { Time: } \\
\text { Place: } \\
\text { Date: }\end{array}$ \\
\hline Round & My Harvest Decision \\
\hline Practice 1 & \\
\hline Practice 2 & \\
\hline Practice 3 & \\
\hline 1 & \\
\hline 2 & \\
\hline 3 & \\
\hline 4 & \\
\hline 5 & \\
\hline 6 & \\
\hline 7 & \\
\hline 8 & \\
\hline 9 & \\
\hline 10 & \\
\hline
\end{tabular}




\section{Player calculation sheet Player no: \\ Time: \\ Place: \\ Date:}

\begin{tabular}{|l|l|l|l|}
\hline Round & A & B & \\
\cline { 2 - 4 } & $\begin{array}{c}\text { My } \\
\text { Harvest } \\
\text { decision }\end{array}$ & $\begin{array}{c}\text { Fine } \\
(0 \text { or A+3) }\end{array}$ & $\begin{array}{c}\text { My points } \\
\text { (A-B) }\end{array}$ \\
\hline 1 & & & \\
\hline 2 & & & \\
\hline 3 & & & \\
\hline 4 & & & \\
\hline 5 & & & \\
\hline 6 & & & \\
\hline 7 & & & \\
\hline 8 & & & \\
\hline 9 & & & \\
\hline 10 & & & \\
\hline
\end{tabular}

